\title{
Enhancing effects of salicylate on quinidine-induced block of human wild type and LQT3 related mutant cardiac $\mathrm{Na}^{+}$channels
}

\author{
Tadashi Urashima ${ }^{1}$, Yasutaka Kurata 2 , Junichiro Miake ${ }^{3}$, Masaru Kato ${ }^{3}$, Kazuyoshi Ogura ${ }^{3}$, Akio Yano ${ }^{3}$, \\ Masamitsu Adachi ${ }^{3}$, Yasunori TANAKA ${ }^{4}$, Kensaku Yamada ${ }^{3}$, Toshihiro Hamada ${ }^{3}$, Einosuke Mizuta ${ }^{3}$, Masanari \\ Kumabara $^{1}$, Masahiko Kato ${ }^{3}$, Yasutaka Yamamoto ${ }^{1}$, Kazuhide Ogino ${ }^{3}$, Akio Yoshida ${ }^{1}$, Yasuaki Shirayoshi, \\ and Ichiro HisATOME ${ }^{1}$ \\ ${ }^{1}$ Division of Regenerative Medicine and Therapeutics, Institute of Regenerative Medicine and Biofunction, Tottori University Graduate \\ School of Medical Science, Japan; ${ }^{2}$ Department of Physiology, Kanazawa Medical University, Japan; ${ }^{3}$ Division of Cardiology, Tottori \\ University Hospital, Japan; and ${ }^{4}$ Division of Cardiology, Hakuai Hospital, Japan
}

(Received 10 June 2011; and accepted 15 July 2011)

\begin{abstract}
It is unknown whether salicylate enhances the action of antiarrhythmic agents on human $\mathrm{Na}^{+}$ channels with state dependency and tissue specificity. We therefore investigated effects of salicylate on quinidine-induced block of human cardiac and skeletal muscle $\mathrm{Na}^{+}$channels. Human cardiac wild-type (hH1), LQT3-related mutant ( $\triangle \mathrm{KPQ}$ ), and skeletal muscle (hSkM1) $\mathrm{Na}^{+}$channel $\alpha$ subunits were expressed in COS7 cells. Effects of salicylate on quinidine-induced tonic and usedependent block of $\mathrm{Na}^{+}$channel currents were examined by the whole-cell patch-clamp technique. Salicylate enhanced the quinidine-induced tonic and use-dependent block of both hH1 and hSkM1 currents at a holding potential (HP) of $-100 \mathrm{mV}$ but not at $-140 \mathrm{mV}$. Salicylate decreased the $\mathrm{IC}_{50}$ value for the quinidine-induced tonic block of $\mathrm{hH} 1$ at an $\mathrm{HP}$ of $-100 \mathrm{mV}$, and produced a negative shift in the steady-state inactivation curve of hH1 in the presence of quinidine. According to the modulated receptor theory, it is probable that salicylate decreases the dissociation constant for quinidine binding to inactivated-state channels. Furthermore, salicylate significantly enhanced the quinidine-induced tonic and use-dependent block of the peak and steady-state $\triangle \mathrm{KPQ}$ channel currents. The results suggest that salicylate enhances quinidine-induced block of $\mathrm{Na}^{+}$channels via increasing the affinity of quinidine to inactivated state channels.
\end{abstract}

Acetylsalicylic acid, the most widely studied antiplatelet drug, suppresses platelet aggregation by inhibiting cyclo-oxygenase. Salicylic acid $\left(\mathrm{C}_{6} \mathrm{H}_{4}(\mathrm{OH}) \mathrm{COOH}\right)$ belongs to the group of aromatic monocarboxylic acids, which by themselves do not have an anesthetic action. However, monocarboxylic acids such as salicylic, benzoic, acetic, propionic and butyric acid have been reported to enhance the action of local anesthetics $(7,13)$. In particular, monocarboxylic

Address correspondence to: Dr. Yasutaka Kurata Department of Physiology, Kanazawa Medical University, Japan

Tel: +81-76-286-8010, Fax: +81-76-286-2211

E-mail: yasu@kanazawa-med.ac.jp acids containing a lipophilic moiety such as an aliphatic hydrocarbon chain or aromatic ring can enhance the action of local anesthetics in nerves; indeed, salicylate has been reported to enhance the blocking action of procainamide on sodium $\left(\mathrm{Na}^{+}\right)$ channels in nerves (7). And Katsuki et al. (13) demonstrated that salicylate decreased the intracellular $\mathrm{pH}$, which resulted in an increase of the proportion of charged molecules of procaine and the enhancement of its local anesthetic action on nerves.

As for the effect of salicylate on cardiac myocytes, Tanaka et al. (23) reported that it enhanced the action of $\mathrm{Na}^{+}$channel blockers with higher liposolubility by increasing their affinity for inactivated state channels. Since $\mathrm{Na}^{+}$channels in individual 
states might have different drug-binding properties based on their state-dependent conformations, salicylate could modify the state-dependent blocking action of $\mathrm{Na}^{+}$channel blockers. Native $\mathrm{Na}^{+}$channels consist of a tissue-specific $\alpha$ subunit and a $\beta_{1}$ and/or $\beta_{2}$ subunit $(6,15)$. It has been reported that the heart type $\mathrm{Na}^{+}$channel $\left(\mathrm{hH} 1-\beta_{1}\right)$ was threefold more sensitive to resting state block by lidocaine than skeletal muscle type $\mathrm{Na}^{+}$channels $\left(\mu 1-\beta_{1}\right)$, indicating that structural differences within the $\mathrm{Na}^{+}$channel $\alpha$ subunit can determine the tissue-specific sensitivity of cardiac and skeletal muscle $\mathrm{Na}^{+}$channels to blockers. However, it remains unknown whether salicylate can enhance the action of $\mathrm{Na}^{+}$channel blockers on $\mathrm{Na}^{+}$channel $\alpha$ subunits in a state-dependent manner or regardless of the specificity of the subunits.

Upon membrane depolarization, wild-type $\mathrm{Na}^{+}$ channels open briefly and are then rapidly inactivated; they fail to reopen during maintained membrane depolarization, i.e., fast inactivation is absorbing. On the other hand, a mutation in SCN5A (official name: sodium channel, voltage-gated, type $\mathrm{V}$, alpha subunit) gene encoding the $\alpha$ subunit of cardiac $\mathrm{Na}^{+}$ channels, $\triangle \mathrm{KPQ}$ mutation (deletion mutation of nine bases that encode for Lys1505, Pro1506 and Gln 1507 in the highly conserved portion of the III-IV linker that plays a central role in inactivation) yields reopening from the inactivated state, giving rise to a steady-state current $(17,26)$. Thus, $\triangle \mathrm{KPQ}$ mutant channels are considered to cause a congenital form of long-QT syndrome type 3 (LQT3). $\triangle \mathrm{KPQ}$ mutant channels have been reported to have higher resting state affinity than wild-type channels for the class I antiarrhythmic agents flecainide and mexiletine (17, 26 ), indicating the beneficial roles of these agents in preventing the occurrence of life-threatening arrhythmias in LQT3 patients. However, it remains unknown whether salicylate can enhance the actions of $\mathrm{Na}^{+}$channel blockers on $\triangle \mathrm{KPQ}$ channels.

In the present study, we first studied whether salicylate could enhance the quinidine-induced block of human $\mathrm{Na}^{+}$channel $\alpha$ subunits with different tissue-specific structures. Secondly, we compared the enhancing effect of salicylate on the quinidine-induced block of $\triangle \mathrm{KPQ}$ mutant channels with that on the block of wild-type channels.

\section{MATERIALS AND METHODS}

Cell culture and transfection conditions. The vector pRC/CMV (Invitrogen, San Diego, CA, USA) was used as the expression vector for wild skeletal muscle type (hSkM1), wild heart type (hH1) and $\triangle \mathrm{KPQ}$ mutant $\mathrm{Na}^{+}$channel $\alpha$ subunit cDNAs, which were provided by Dr. Naomasa Makita. COS7 cells were routinely maintained in Dullbecco's modified Eagle medium (DMEM; GIBCO, Grand Island, NY) containing $10 \%$ fetal bovine serum, $2 \mathrm{mmol} / \mathrm{L}$ L-glutamine, and $1 \%$ penicillin and streptomycin. Cell cultures were kept at $37^{\circ} \mathrm{C}$ in a $5 \% \mathrm{CO}_{2}$ incubator. Cells grown on glass coverslips in $30 \mathrm{~mm}$ dishes were transfected with hSkM1, hH1, or $\triangle \mathrm{KPQ}$ mutant cDNA along with green fluorescence protein cDNA (Invitrogen) as a marker to identify the transfected cells using lipofectamine method. After $48 \mathrm{~h}$, transiently transfected cells were visualized by the fluorescence light, and subsequently electrophysiological recordings were performed using the cells expressing green fluorescence proteins (8).

Electrophysiological recordings in cultured cells. Whole-cell patch clamp experiments were performed at $22^{\circ} \mathrm{C}$ as described previously (27). The external solution had the following composition $(\mathrm{mmol} / \mathrm{L})$ : $\mathrm{NaCl} 140, \mathrm{CsCl} 5.0, \mathrm{MgCl}_{2} 1.0, \mathrm{CaCl}_{2}$ 1.8, HEPES 10 and glucose 10 (pH 7.4 with $\mathrm{NaOH}$ ). Patchclamp electrodes were filled with an internal solution of the following composition $(\mathrm{mmol} / \mathrm{L})$ : $\mathrm{CsF}$ 90, $\mathrm{CsCl} 10, \mathrm{CsEGTA} 10, \mathrm{NaF} 10, \mathrm{MgCl}_{2} 2$ and HEPES 10 (pH 7.4 with $\mathrm{CsOH})$.

Determination of tonic and use-dependent block of $\mathrm{Na}^{+}$channel by quinidine. Blockade of $\mathrm{Na}^{+}$channel currents by its inhibitors was evaluated in two different ways, i.e., by estimating its tonic block and use-dependent block (UDB). The tonic block was defined as the drug-induced decrease in the current mediated by $\mathrm{Na}^{+}$channel $\alpha$ subunits determined at a low pulse frequency of $0.1 \mathrm{~Hz}$, which was sufficiently low to eliminate UDB of the drug $(9,10)$. $\mathrm{Na}^{+}$channel currents were elicited by $30 \mathrm{~ms}$ depolarization to $-20 \mathrm{mV}$ from a holding potential (HP) of -140 or $-100 \mathrm{mV}$. The amount of tonic block was calculated as the \% decrease in peak currents during perfusion of a drug with respect to the control currents. The zero current level was obtained after application of $100 \mu \mathrm{M}$ tetrodotoxin. To determine the values of $\mathrm{IC}_{50}$ and Hill coefficient, the concentration dependence data for the peak current was fitted with the following Hill equation:

$$
\% \text { tonic block }=1 /\left[\left(\mathrm{IC}_{50} /[\mathrm{D}]\right)^{\mathrm{n}}+1\right],
$$

where [D] is the drug concentration, with $\mathrm{IC}_{50}$ and $\mathrm{n}$ being the apparent dissociation constant and Hill coefficient, respectively. 
To study the drug-induced shift in the voltagedependent inactivation kinetics of $\mathrm{Na}^{+}$channels, the steady-state inactivation $\left(h_{\infty}\right)$ curve was determined under control conditions and during exposure to the agent using the following standard two-pulse protocol: A $1000-\mathrm{ms}$ conditioning pulse to a designated level of membrane potential was followed by a 0.1 -ms interpulse interval and then a 30 -ms test pulse to $-20 \mathrm{mV}$, which was applied every $10 \mathrm{~s}$ (at $0.1 \mathrm{~Hz}$ ). The data points were fitted by the following Boltzmann equation:

$$
\mathrm{h}_{\infty}=\left(1+\exp \left[\left(\mathrm{V}_{\mathrm{m}}-\mathrm{V}_{\mathrm{h}}\right) / \mathrm{k}\right]\right)^{-1},
$$

where $\mathrm{V}_{\mathrm{m}}$ is the prepulse potential, with $\mathrm{V}_{\mathrm{h}}$ and $\mathrm{k}$ being the half-maximum prepulse potential and slope factor, respectively.

To study the UDB of $\mathrm{Na}^{+}$channel currents, the currents elicited by a train of 20 depolarizing pulses of $30 \mathrm{~ms}$ from an $\mathrm{HP}$ of -100 or $-140 \mathrm{mV}$ to $-20 \mathrm{mV}$ were recorded at various frequencies. The peak current amplitude decreased during a pulse train and reached a new steady state. The amount of UDB was calculated as the \% decrease of the current in the new steady state with respect to that of the first pulse $(9,10)$.

Drugs. Salicylate-sodium (Nakarai Chemical, Tokyo, Japan) and quinidine (Nakarai Chemical) were used in this study. Salicylate did not change the $\mathrm{pH}$ of the solution even at the highest concentration $(3 \mathrm{mM})$ used in this study $(\mathrm{pH}=7.35 \pm 0.05$ in control, and $7.34 \pm 0.02$ in the presence of $3 \mathrm{mM}$ salicylate: $\mathrm{n}=4$ each).

Data analysis. Analysis of the data was performed on a personal computer (Macintosh LC630) using a custom-made software. All curve fittings were done with a non-linear least square algorithm using a Marquardt routine. The results were expressed as the mean \pm SEM. Statistical significance was determined using the one-way analysis of variance (ANOVA) test, and the difference was considered to be significant when the $P$ value was less than 0.05 .

Determination of binding constants for quinidine with a state model of $\mathrm{Na}^{+}$channel. To elucidate the kinetic mechanism underlying the enhancement of quinidine-induced $\mathrm{Na}^{+}$channel block by salicylate, we determined the dissociation constants $\left(\mathrm{K}_{\mathrm{d}}\right)$ for quinidine binding to the resting $\left(\mathrm{K}_{\mathrm{dR}}\right)$ and inactivated $\left(\mathrm{K}_{\mathrm{dI}}\right)$ states of the $\mathrm{Na}^{+}$channel $(\mathrm{hH} 1)$ using a state model (Scheme 1 in Fig. 8A) and tonic block data. As described previously $(3,12)$, the voltagedependent inactivation curve of $\mathrm{Na}^{+}$channels (with quinidine) and concentration dependence of quinidine-induced tonic block were calculated for different $K_{d}$ values; the $K_{d I}$ value was determined for the state model to reproduce the experimental $\mathrm{V}_{\mathrm{h}}$ and $\mathrm{IC}_{50}$ values, with the $\mathrm{K}_{\mathrm{dR}}$ value set equal to the experimental $\mathrm{IC}_{50}$ at an $\mathrm{HP}$ of $-140 \mathrm{mV}$. Rate constants for state transitions were formulated as functions of the Gibbs free energy composed of chemical and potential terms, as described in our previous articles $(1,23)$.

\section{RESULTS}

Effects of salicylate on the tonic block of human $\mathrm{Na}^{+}$channel currents by quinidine

Fig. 1 shows the enhancing effect of salicylate on quinidine-induced tonic block of hH1 currents elicited by $30-\mathrm{ms}$ test pulses to $-20 \mathrm{mV}$ at $0.1 \mathrm{~Hz}$ with different HPs of -100 and $-140 \mathrm{mV}$. Quinidine at $6 \mu \mathrm{M}$ decreased hH1 currents by $37 \%$ at an HP of $-100 \mathrm{mV}$ (Fig. 1A, a: control, b: +quinidine). Addition of $1 \mathrm{mM}$ salicylate enhanced quinidine-induced tonic block of $\mathrm{hH} 1$ currents, with the peak current being decreased by $60 \%$ (Fig. 1A, c). Washout of both quinidine and salicylate restored $\mathrm{hH} 1$ currents partially (Fig. 1A, d). With an HP of $-140 \mathrm{mV}, 6 \mu \mathrm{M}$ quinidine blocked hH1 currents by $24 \%$ (Fig. 1B, e: control and f: +quinidine); addition of $1 \mathrm{mM}$ salicylate did not enhance its block of $\mathrm{hHl}$ currents at this HP (Fig. 1B, g).

Fig. $1 \mathrm{C}$ and $\mathrm{D}$ show the concentration dependence of the tonic block of $\mathrm{hH} 1$ currents by quinidine $(0.06$ to $600 \mu \mathrm{M})$ in the absence and presence of $1 \mathrm{mM}$ salicylate at an HP of -100 or $-140 \mathrm{mV}$. At an HP of $-100 \mathrm{mV}, 1 \mathrm{mM}$ salicylate significantly enhanced the tonic block of $\mathrm{hH} 1$ by quinidine at various concentrations, resulting in a significantly smaller $\mathrm{IC}_{50}$ value for the quinidine-induced tonic block $(6.0 \mu \mathrm{M})$ than that without salicylate $(14.56 \mu \mathrm{M})$, as shown in Fig. 1C. In contrast, at an $\mathrm{HP}$ of $-140 \mathrm{mV}$, salicylate did not cause a significant shift in the concentration dependence of the quinidine block (control: $\mathrm{IC}_{50}=$ $21.87 \mu \mathrm{M}$, +salicylate: $\left.\mathrm{IC}_{50}=19.46 \mu \mathrm{M}\right)$, as shown in Fig. 1D. These results suggest that salicylate increases the affinity of quinidine to the inactivated state of $\mathrm{hH} 1$.

Fig. 2 shows the steady-state inactivation curves of hH1 currents under control conditions, in the presence of $6 \mu \mathrm{M}$ quinidine alone, and in the presence of both $6 \mu \mathrm{M}$ quinidine and $1 \mathrm{mM}$ salicylate. $\mathrm{V}_{\mathrm{h}}(\mathrm{k})$ values were $-69.4 \pm 5.4 \mathrm{mV}(\mathrm{k}=6.4)$ under 
A Holding Potential $=-100 \mathrm{mV}$<smiles>C=CCC(C)CC(C)C(C)C(C)C</smiles>

C

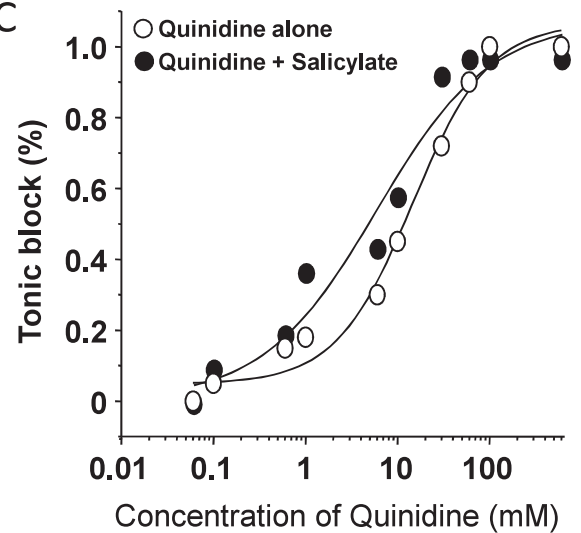

B Holding Potential $=-140 \mathrm{mV}$
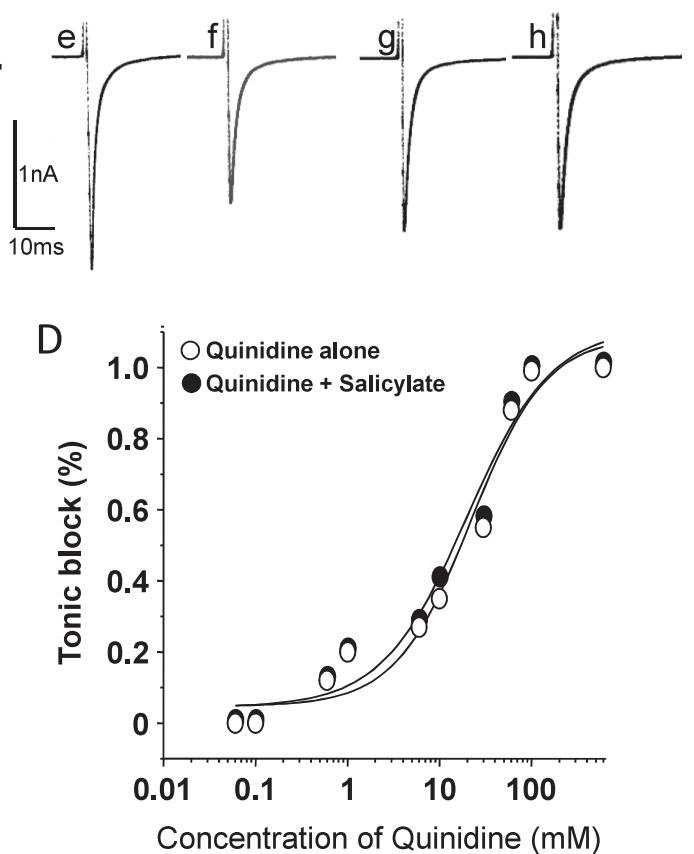

Fig. 1 Effects of salicylate on concentration dependence of the quinidine-induced tonic block of hH1 currents at different HPs. A, B: Original current traces. a and e: $\mathrm{hH} 1$ currents elicited by the test pulses to $-30 \mathrm{mV}$ at $0.1 \mathrm{~Hz}$ from an $\mathrm{HP}$ of either -100 (a) or -140 (e) $\mathrm{mV}$. $\mathbf{b}$ and $\mathbf{f}$ : $\mathrm{hH} 1$ currents recorded in the presence of $6 \mu \mathrm{M}$ quinidine with a HP of either -100 (b) or -140 (f) $\mathrm{mV}$. c and $\mathbf{g}$ : $\mathrm{hH} 1$ currents recorded in the presence of both $6 \mu \mathrm{M}$ quinidine and $1 \mathrm{mM}$ salicylate with a HP of either -100 (c) or $-140(\mathrm{~g}) \mathrm{mV}$. $\mathbf{d}$ and $\mathbf{h}$ : $\mathrm{hH} 1$ currents recorded after washout of quinidine and salicylate. The vertical and horizontal bars indicate $1 \mathrm{nA}$ and $10 \mathrm{~ms}$, respectively. C, D: The concentration-dependent tonic block of hH1 currents by quinidine in the absence and presence of $1 \mathrm{mM}$ salicylate, determined at $\mathrm{HP}=-100 \mathrm{mV}(\mathrm{C})$ or $-140 \mathrm{mV}(\mathrm{D})$. The ordinate indicates \% tonic block of $\mathrm{hH} 1$ and the abscissa indicates the log value of quinidine concentrations $(0.06-600 \mu \mathrm{M})$. Open circles and closed circles indicate the data for quinidine alone and for quinidine plus $1 \mathrm{mM}$ salicylate, respectively $(n=8$ for each concentration).

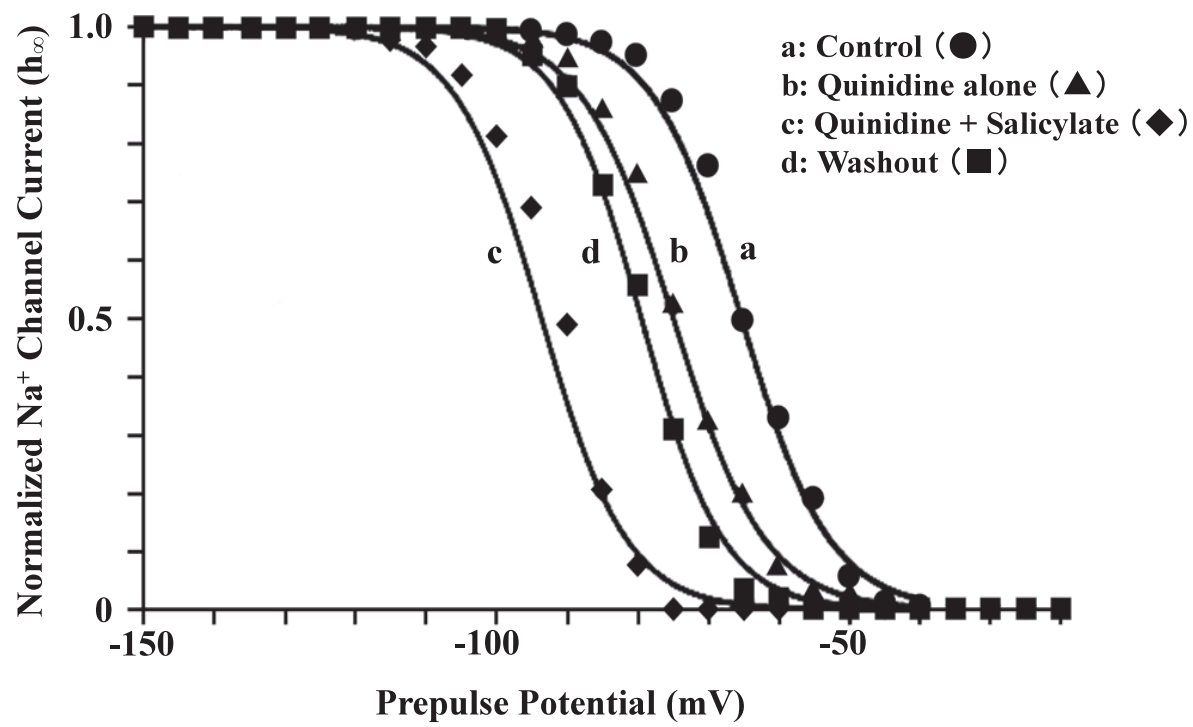

Fig. 2 Effects of salicylate on the quinidine-induced shift in the inactivation curve of hH1 currents. Circles, control conditions; triangles, $6 \mu \mathrm{M}$ quinidine; diamonds, $6 \mu \mathrm{M}$ quinidine plus $1 \mathrm{mM}$ salicylate; squares, washout. The ordinate indicates the availability of $\mathrm{hH} 1$ and the abscissa the conditioning potentials. 
the control conditions, $-80.0 \pm 4.0 \mathrm{mV}(\mathrm{k}=6.0)$ in the presence of quinidine alone, $-91.8 \pm 1.3 \mathrm{mV}(\mathrm{k}=$ $6.1)$ in the presence of both the agents, and $-78.0 \pm$ $3.7 \mathrm{mV}(\mathrm{k}=6.0)$ after the washout. These results indicate that salicylate also produced a significant shift of voltage-dependent hH1 inactivation toward the hyperpolarized direction, while the slope factor $\mathrm{k}$ remained unchanged.

Fig. 3 shows the summary of the enhancing effects of salicylate on quinidine-induced tonic block of $\mathrm{hH} 1$ in comparison with those on quinidine-induced tonic block of hSkM1 at an HP of -100 or $-140 \mathrm{mV}$. Salicylate significantly enhanced the quinidine-induced tonic block of wild-type $\mathrm{hH} 1$ and $\mathrm{hSkM1}$ at $\mathrm{HP}=-100 \mathrm{mV}$ but not at $\mathrm{HP}=-140 \mathrm{mV}$.

As shown in Fig. 4, the salicylate-induced enhancement of the quinidine block was well reproduced by the state model for $\mathrm{Na}^{+}$channels (Scheme 1 in Fig. 8) when salicylate was assumed to increase the affinity of quinidine to the inactivated state (i.e., reduce the $\mathrm{K}_{\mathrm{dI}}$ ). Decreasing the $\mathrm{K}_{\mathrm{dI}}$ yielded apparent reduction in the $\mathrm{IC}_{50}$ at $\mathrm{HP}=-100 \mathrm{mV}$ and a negative shift in the $\mathrm{V}_{\mathrm{h}}$. The state model with the $\mathrm{K}_{\mathrm{dI}}$ values of 0.70 and $0.11 \mu \mathrm{M}\left(\mathrm{K}_{\mathrm{dR}}=19.46 \mu \mathrm{M}\right)$ predicted the $\mathrm{V}_{\mathrm{h}}$ of -82.1 and $-93.2 \mathrm{mV}$, respectively $(\mathrm{k}=6.4)$; and the $\mathrm{IC}_{50}$ of 16.2 and $8.3 \mu \mathrm{M}$, respectively. These predicted values of the $\mathrm{V}_{\mathrm{h}}$ and $\mathrm{IC}_{50}$ are very close to the experimentally determined ones. Thus, salicylate was suggested to yield more than 6-fold increase in the affinity of quinidine to inactivated $\mathrm{hH} 1$ channels. Taken together, salicylate appears to increase the binding affinity of quinidine to inactivated $\mathrm{Na}^{+}$channel $\alpha$ subunits and enhance its tonic block without tissue specificity.

\section{Effects of salicylate on UDB of human $\mathrm{Na}^{+}$channel currents by quinidine}

Fig. 5A shows the enhancing effect of salicylate on the quinidine-induced UDB of hH1 currents elicited by a train of $30-\mathrm{ms}$ depolarizing pulses to $-20 \mathrm{mV}$ from an HP of either -100 or $-140 \mathrm{mV}$ at $2 \mathrm{~Hz}$. The currents elicited by the first depolarizing pulse (open circles) and by the 20th pulse (closed circles) in the absence or presence of $1 \mathrm{mM}$ salicylate are illustrated. At an $\mathrm{HP}$ of $-100 \mathrm{mV}, 6 \mu \mathrm{M}$ quinidine produced a UDB of peak hH1 currents by $7 \%$ (Fig. 5A, a). The addition of $1 \mathrm{mM}$ salicylate enhanced the UDB of hH1 by $6 \mu \mathrm{M}$ quinidine, which reduced the peak current by $19 \%$ (Fig. 5A, b). In contrast, at an HP of $-140 \mathrm{mV}, 6 \mu \mathrm{M}$ quinidine produced a UDB of
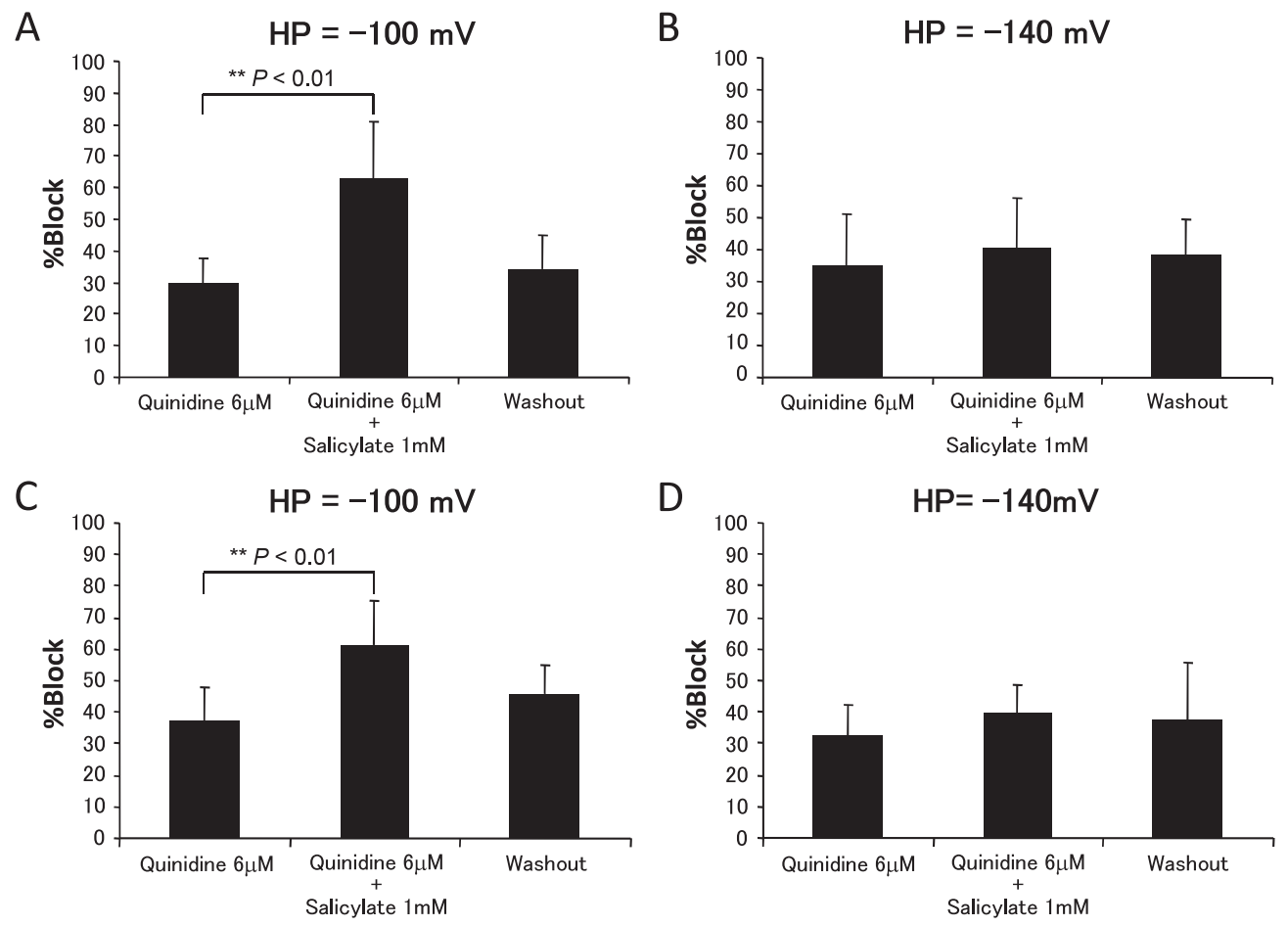

Fig. 3 Enhancing effects of salicylate on the tonic block of $\mathrm{hH} 1$ and $\mathrm{hSKM} 1$ currents by quinidine at the different HPs. A, B: The summary of the \% tonic block of peak $\mathrm{hH} 1$ currents by quinidine in the absence and presence of $1 \mathrm{mM}$ salicylate at $\mathrm{HP}=-100 \mathrm{mV}(\mathrm{A})$ and $-140 \mathrm{mV}(\mathrm{B}) . \mathrm{n}=6$ each, ${ }^{\star \star} P<0.01$. C, D: The summary of the $\%$ tonic block of peak hSkM1 currents by quinidine in the absence and presence of $1 \mathrm{mM}$ salicylate at $\mathrm{HP}=-100 \mathrm{mV}(\mathrm{C})$ and $-140 \mathrm{mV}(\mathrm{D}) . \mathrm{n}=6$ each, ${ }^{\star \star} P<0.01$. 

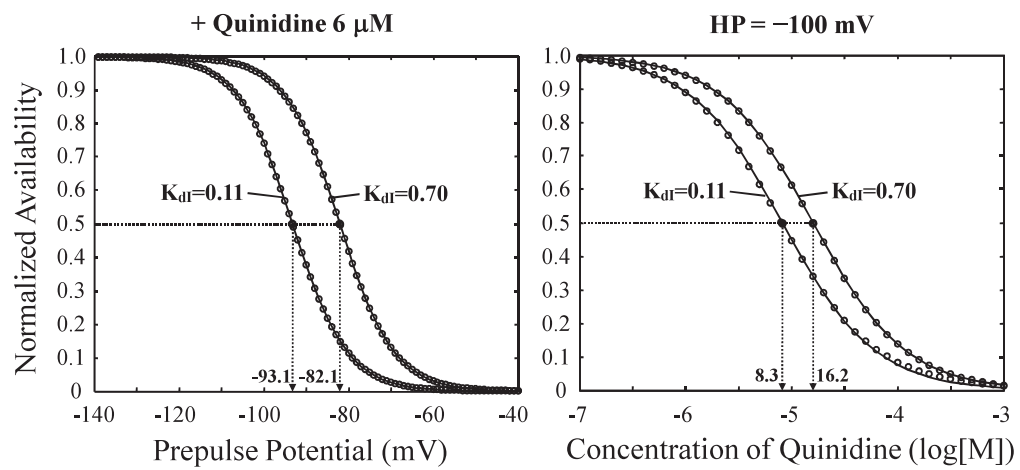

Fig. 4 Predicted voltage-dependent inactivation curve of the $\mathrm{hH} 1$ channel (with $6 \mu \mathrm{M}$ quinidine) and concentration dependence of quinidine-induced tonic block (at HP $=-100 \mathrm{mV}$ ) for the $\mathrm{K}_{\mathrm{dl}}$ value of 0.70 and $0.11 \mu \mathrm{M}\left(\mathrm{K}_{\mathrm{dR}}=21.87 \mu \mathrm{M}\right)$. Steadystate probability of a channel to be in the drug-free resting state (state $R$ in Scheme 1) was calculated and normalized as described previously (23). The rate constants for the transition between the resting and inactivated states of $\mathrm{hH} 1 \mathrm{channels}$ are the same as used in Miake et al. (16); the Gibbs free energy peak for the quinidine unbinding (dissociation from the channel) was assumed to be 34 (in RT unit). The open circles and lines indicate the predicted probabilities of state R (normalized to the maximum) and their fits with Eq. 1 or 2 , respectively. The numbers at the bottom represent the $V_{h}$ and $I C_{50}$ values determined by the fittings.
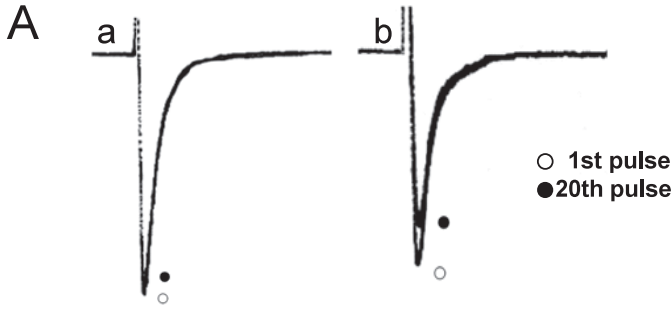

B

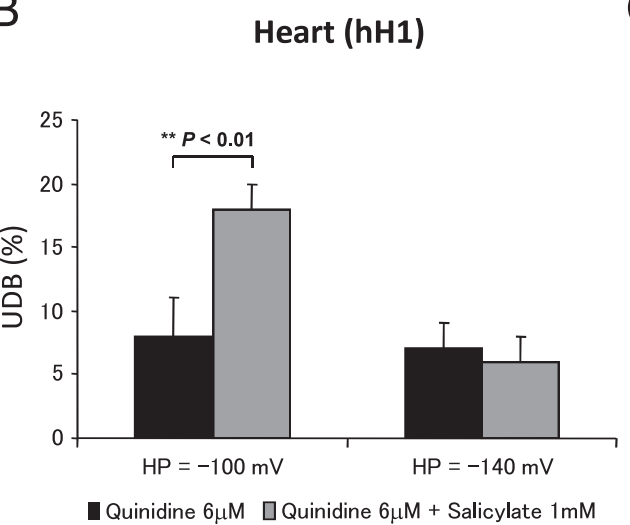

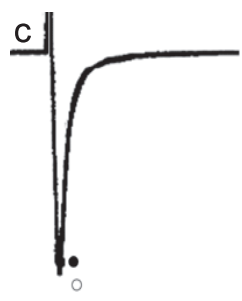

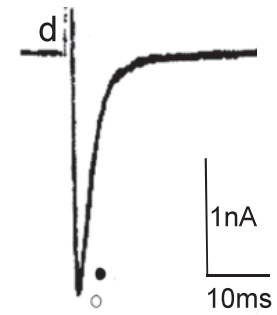

C

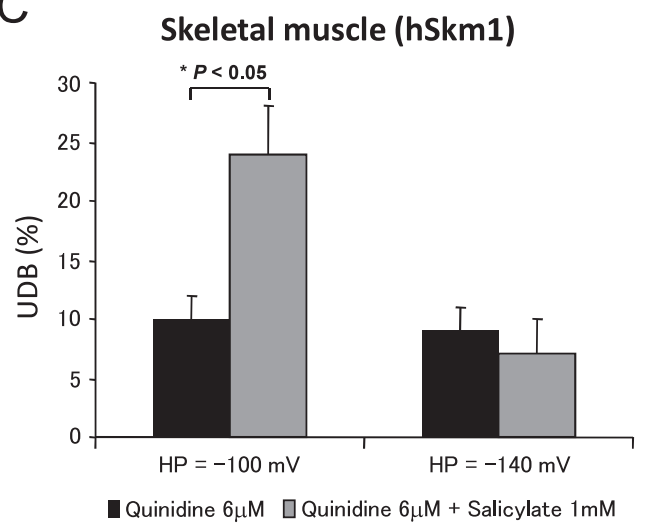

Fig. 5 Effects of salicylate on the use-dependent block (UDB) of hH1 and hSkM1 currents by quinidine at different HPs. A: $\mathrm{hH} 1$ currents elicited by a train of $30 \mathrm{~ms}$ depolarizing pulses to $-20 \mathrm{mV}$ at $2 \mathrm{~Hz}$ from a HP of -100 (a, b) or -140 (c, d) $\mathrm{mV}$. Open and closed circles indicate the peak $\mathrm{hH} 1$ currents elicited by the first depolarizing pulse and by the 20th pulse, respectively. Currents were evoked in the presence of $6 \mu \mathrm{M}$ quinidine alone $(\mathrm{a}, \mathrm{c})$ or in the presence of both $6 \mu \mathrm{M}$ quinidine and $1 \mathrm{mM}$ salicylate $(\mathrm{b}, \mathrm{d})$. B, C: The summary of the salicylate effects on UDB of $\mathrm{hH} 1$ (B) and hSkM1 (C) currents by quinidine at $\mathrm{HP}=-100 \mathrm{mV}$ and $-140 \mathrm{mV}$. UDB was tested in the presence of $6 \mu \mathrm{M}$ quinidine alone (closed column) or in the presence of both $6 \mu \mathrm{M}$ quinidine and $1 \mathrm{mM}$ salicylate (shaded column). $\mathrm{n}=6$ each; ${ }^{\star} P<0.05,{ }^{\star *} P<0.01$.

$6 \%$ (Fig. 5A, c), with the addition of $1 \mathrm{mM}$ salicylate not enhancing the UDB of hH1 by quinidine (Fig. 5A, d). Fig. 5B shows the summary of the en- hancing effects of salicylate on the UDB ( $n=6$ for each group). Salicylate at $1 \mathrm{mM}$ could significantly enhance the UDB by $6 \mu \mathrm{M}$ quinidine at an HP of 

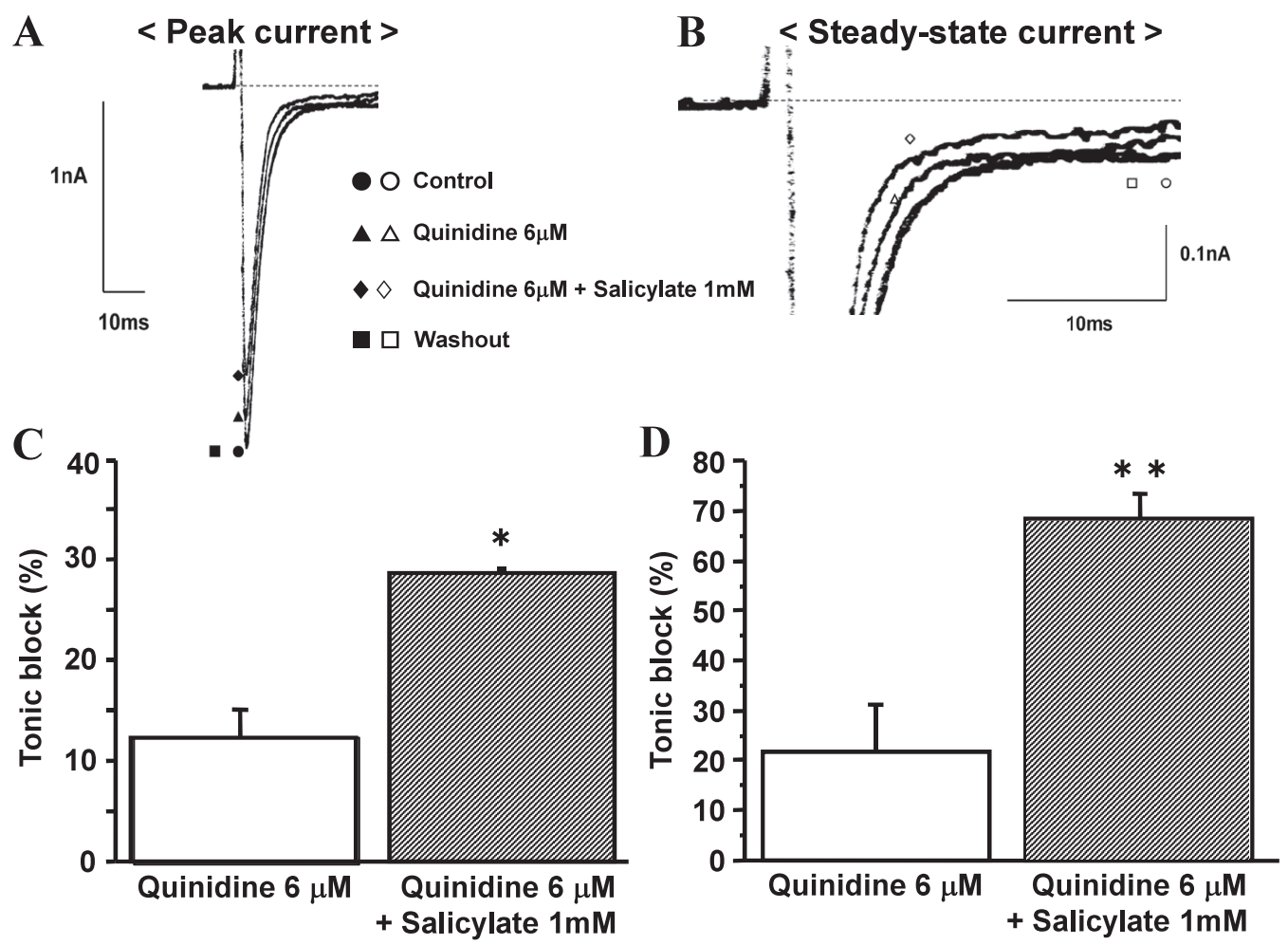

Fig. 6 Enhancing effects of salicylate on quindine-induced tonic block of $\triangle K P Q$ peak and steady-state currents. A, B: Peak (A) and steady-state (B) $\triangle \mathrm{KPQ}$ currents elicited by $30 \mathrm{~ms}$ depolarizing pulses to $-20 \mathrm{mV}$ from a $\mathrm{HP}$ of $-100 \mathrm{mV}$ at $0.1 \mathrm{~Hz}$ in control (circles), in the presence of $6 \mu \mathrm{M}$ quinidine alone (triangles), in the presence of $6 \mu \mathrm{M}$ quidine plus $1 \mathrm{mM}$ salicylate (diamonds), and washout (squares). C, D: The summary of the quinidine block of peak (C) and steady-state (D) $\triangle K P Q$ currents in the absence and presence of $1 \mathrm{mM}$ salicylate $\left(\mathrm{n}=8\right.$ each). ${ }^{*} P<0.05,{ }^{* *} P<0.001$ (vs. quinidine alone).

$-100 \mathrm{mV}(7 \pm 3 \%$ without salicylate vs. $23 \pm 3 \%$ with $1 \mathrm{mM}$ salicylate; $P<0.05)$, but not at an HP of $-140 \mathrm{mV}(7 \pm 2 \%$ without salicylate vs. $6 \pm 2 \%$ with $1 \mathrm{mM}$ salicylate). Salicylate also enhanced the quinidine-induced UDB of hSkM1 (Fig. 5C). Salicylate at $1 \mathrm{mM}$ could significantly enhance the UDB of hSkM1 by $6 \mu \mathrm{M}$ quinidine at $\mathrm{HP}=-100 \mathrm{mV}(10 \pm$ $2 \%$ without salicylate vs. $24 \pm 10 \%$ with $1 \mathrm{mM}$ salicylate; $P<0.05)$, but not at $\mathrm{HP}=-140 \mathrm{mV}(8 \pm$ $2 \%$ without salicylate vs. $7 \pm 3 \%$ with $1 \mathrm{mM}$ salicylate). These results indicate that salicylate enhances the UDB by quinidine of $\mathrm{Na}^{+}$channel $\alpha$ subunits without isoform specificity.

Effects of salicylate on quinidine-induced tonic block and $U D B$ of $\triangle K P Q$ channel currents

LQT3-related $\triangle K P Q$ mutant current is composed of peak current (Fig. 6A) and steady-state current (Fig. 6B); the former represents the transition to the absorbing inactivated state and the latter represents the reopening of $\mathrm{Na}^{+}$channels in the burst mode (Scheme 2 in Fig. 8). Studying the interaction of local anesthetics with $\triangle \mathrm{KPQ}$ clarified their state- dependent block of the mutant $\mathrm{Na}^{+}$channel $(2,12$, 17, 25, 26). As shown in Fig. $6 \mathrm{~A}, 6 \mu \mathrm{M}$ quinidine reduced the peak current by $10 \%$, and salicylate produced the further block of $23 \%$. Quinidine at $6 \mu \mathrm{M}$ also reduced the steady-state current by $38 \%$, with salicylate producing the further block of $78 \%$ (Fig. 6B). Washout of both the agents restored the peak and steady-state current almost completely. Fig. $6 \mathrm{C}$ and D show the summary of the effects of salicylate on the quinidine-induced tonic block of $\triangle K P Q$. Salicylate significantly enhanced the quinidine block of peak currents from $13 \pm 2$ to $28 \pm$ $0.5 \%(\mathrm{n}=6)$ and also the quinidine block of steadystate currents from $22 \pm 10$ to $68 \pm 5 \%(n=6)$.

Fig. 7 shows the summary of the enhancing effects of salicylate on quinidine-induced UDB of $\triangle \mathrm{KPQ}$ peak and steady-state currents. Salicylate slightly increased the UDB of peak currents from $25 \pm 7$ to 41 $\pm 5 \%$, while it more dramatically increased the UDB of steady-state currents from $27 \pm 7$ to $65 \pm 9 \%$. 


\section{DISCUSSION}

The enhancing effect of salicylate on quinidineinduced block of $\mathrm{Na}^{+}$channels does not depend on the tissue-specific structures of $\mathrm{Na}^{+}$channels

In a previous study we found that salicylate selectively increased the quinidine-bound inactivated $\mathrm{Na}^{+}$ channels, enhancing thereby both tonic block and UDB by quinidine in guinea-pig ventricular myocytes (23). The structural differences among channel proteins may account for tissue-specific sensitivity

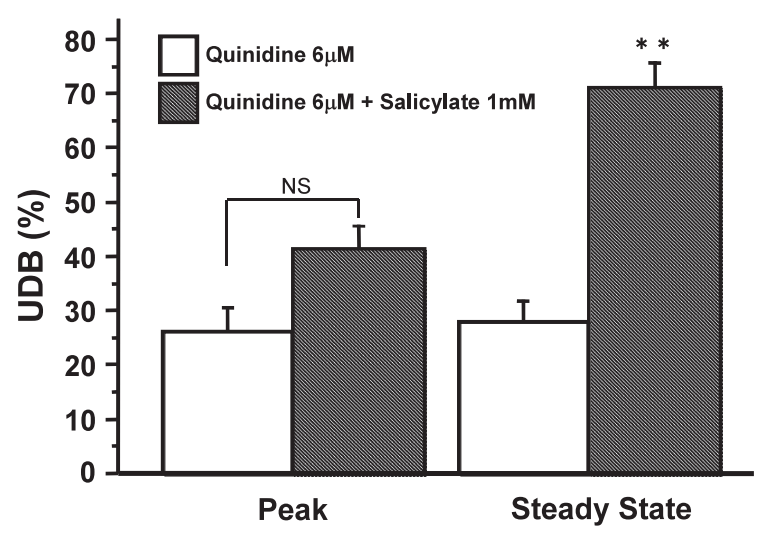

Fig. 7 Enhancing effects of salicylate on quinidine-induced UDB of peak and steady-state $\triangle \mathrm{KPQ}$ currents. Currents were elicited at $2 \mathrm{~Hz}$ in the absence and presence of $1 \mathrm{mM}$ salicylate ( $\mathrm{n}=8$ each). ${ }^{* *} P<0.001$ (vs. quinidine alone). of cardiac and skeletal muscle $\mathrm{Na}^{+}$channels to drugs; e.g., the time course of recovery from inactivation in the presence of lidocaine was much slower in heart type $\mathrm{Na}^{+}$channel $\alpha$ subunit $\left(\mathrm{hH} 1-\beta_{1}\right)$ than in skeletal muscle type $\mathrm{Na}^{+}$channel $\alpha$ subunit $\left(\mu 1-\beta_{1}\right)$ (18). The III-IV linker region that mediates the inactivation process is the most conserved region in various $\mathrm{Na}^{+}$channel isoforms $(3,5,20,21,24)$, while the transmembrane segment S6 of domain IV is important for the resting state block by the local anesthetic etidocaine (11). In the present study, the salicylate-induced enhancement of the tonic block and UDB by quinidine showed voltage dependency but not isoform specificity, indicating that salicylate would increase the binding affinity of quinidine for inactivated $\mathrm{Na}^{+}$channel $\alpha$ subunits through the conserved region of the $\mathrm{Na}^{+}$channel.

The preferential blockade of open/inactivated $\mathrm{Na}^{+}$ channels without tissue specificity by charged local anesthetics is quite reasonable, because the binding of charged local anesthetics to different subtypes of $\mathrm{Na}^{+}$channels is known to be highly conserved. It might also be relevant that flecainide (mostly charged) preferentially suppresses late $\mathrm{Na}^{+}$currents in the LQT3 $\triangle \mathrm{KPQ}$ mutant (17). In the present study, salicylate at the concentration of $\sim 3 \mathrm{mM}$ did not lower the $\mathrm{pH}$ of the external solution. However, the neutral form of salicylate can diffuse into the cell and lower the intracellular $\mathrm{pH}$ (13); inside the
A (Scheme 1)

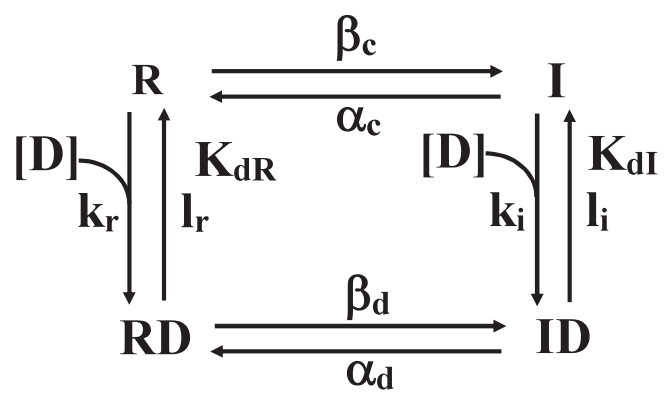

\section{B (Scheme 2)}

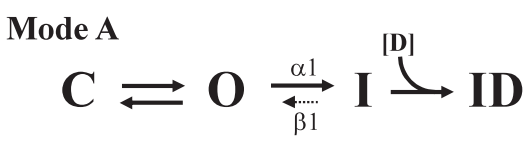

Mode B

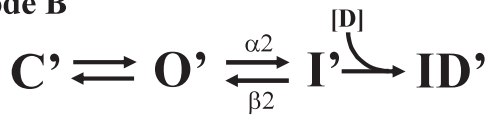

Fig. 8 Markovian state schemes for the gating kinetics of the wild-type and $\triangle K P Q$ mutant $\mathrm{Na}^{+}$channels. $\mathbf{A}$ (Scheme1): $A$ simplified scheme showing the transitions between the rested and inactivated states of the channel and binding of quinidine molecules to each state. D stands for the drug molecule. R and RD are the drug-free and drug-bound resting states, respectively; I and ID are the drug-free and drug-bound inactivated states, respectively. $\mathrm{kr}$ and $\mathrm{ki}$ are the drug binding rate constants for the resting and inactivated states; Ir and li are the corresponding dissociation rate constants. $a$ is the forward rate constant for a transition from state I to $\mathrm{R}\left(a_{\mathrm{c}}\right)$ or from ID to $\mathrm{RD}\left(a_{\mathrm{d}}\right) ; \beta$ is the backward rate constant from $\mathrm{R}$ to I $\left(\beta_{\mathrm{c}}\right)$ or from RD to ID $\left(\beta_{\mathrm{d}}\right) . \mathrm{K}_{\mathrm{dR}}$ and $\mathrm{K}_{\mathrm{dl}}$ are the equilibrium dissociation constants for the resting and inactivated states, respectively $\left(\mathrm{K}_{\mathrm{dR}}=\mathrm{lr} / \mathrm{kr}, \mathrm{Kdl}=\mathrm{li} / \mathrm{ki}\right)$. B (Scheme2): A schematic diagram illustrating two modes of $\triangle \mathrm{KPQ}$ channel gating. Mode $\mathrm{A}$ represents the gating kinetics to yield the peak current of $\triangle K P Q$ mutant, whereas Mode $B$ represents the gating kinetics to yield the steady-state current of $\triangle \mathrm{KPQ}$. In Mode $\mathrm{A}$, the mutant channel open briefly and then inactivate without reopening as the wild-type $\mathrm{hH} 1$ channel, where the backward rate constant $\left(\beta_{1}\right)$ is much smaller than the forward rate constant $\left(a_{1}\right)$. In Mode $\mathrm{B}$, the mutant channel repeatedly transits between an inactivated state (I') and open state $\left(\mathrm{O}^{\prime}\right)$, where the backward rate constant $\left(\beta_{2}\right)$ is significantly larger than that in Mode $A\left(\beta_{1}\right)$. 
cell, therefore, salicylate may increase the proportion of charged quinidine with a pKa of 8.56 enhancing thereby the blocking effect of quinidine.

A state model based on the modulated receptor theory (Scheme 1 in Fig. 8) serves to estimate the binding affinity of drugs to $\mathrm{Na}^{+}$channels in different states. According to this modulated receptor theory $(22), 1)$ drugs bind to a receptor site on or very close to $\mathrm{Na}^{+}$channels; 2) the affinity of drugs to the receptor depends on the channel states, i.e., whether the channel is in the resting, activated, or inactivated state; 3) drug-associated channels differ from drug-free channels in that they are not conductive, and their voltage-dependent ability to be activated is shifted to more negative potentials. It is well known that the tonic block is composed of resting-state block and inactivated-state block (22). We previously reported that salicylate selectively reduced the $\mathrm{K}_{\mathrm{dI}}$ $\left(\mathrm{K}_{\mathrm{d}}\right.$ value of the inactivated state) for quinidine block, increasing thereby the number of drug-bound nonconducting inactivated $\mathrm{Na}^{+}$channels in guineapig ventricular myocytes, because salicylate decreased the $\mathrm{IC}_{50}$ for quinidine block at the depolarized membrane potential but not at the hyperpolarized membrane potential. In the present study, salicylate decreased the $\mathrm{IC}_{50}$ for the quinidine block of $\mathrm{hH} 1$ channels at the depolarized membrane potential $(-100 \mathrm{mV})$ without changes in the $\mathrm{IC}_{50}$ for the blockade at the hyperpolarized potential $(-140 \mathrm{mV})$. Therefore, we concluded that salicylate enhanced the quinidine-induced tonic block of $\mathrm{hH} 1$ channels by decreasing the $\mathrm{K}_{\mathrm{dI}}$ for quinidine block without changing $\mathrm{K}_{\mathrm{dR}}\left(\mathrm{K}_{\mathrm{d}}\right.$ value in the resting state). This would explain the enhancement of the quinidine-induced UDB of hH1 channels by salicylate as well. As the UDB is composed of the activated and/or the inactivated state block, the salicylate-induced increase in the affinity of quinidine for inactivated hH1 channels would lead to an accumulation of quinidine-bound nonconducting hH1 channels during trains of stimuli, resulting in an enhanced UDB by quinidine.

Salicylate strongly enhanced quinidine block of LQT3 related mutant cardiac $\mathrm{Na}^{+}$channels

It is well-known that the inactivation process of $\mathrm{Na}^{+}$ channels has two components, i.e., fast inactivation and slow inactivation. Most wild-type $\mathrm{Na}^{+}$channels in the inactivated state do not reopen during maintained membrane depolarization, i.e., fast inactivation is absorbing. In ventricular myocytes and Purkinje fibers $(4,14,19), \mathrm{Na}^{+}$channels reopen from the inactivated states, produce bursts of channel openings during maintained depolarization, leading to slow inactivation. Salicylate is suggested to selectively decrease the $\mathrm{K}_{\mathrm{dI}}$ for quinidine binding and increase the number of quinidine-bound inactivated channels (State ID in Scheme 1). The channels reopening from the inactivated state frequently transit between the inactivated state and the open state (Mode B in Scheme 2 as shown in Fig. 8B). Salicylate may facilitate quinidine binding to the inactivated state of reopening $\mathrm{Na}^{+}$channels (i.e., State I' in Mode B), as well as its binding to the inactivated state of briefopening $\mathrm{Na}^{+}$channels (State I in Mode A). This facilitation of quinidine binding yields an increase of quinidine-bound inactivated channels (State ID and ID'), leading to enhancement of the tonic block and UDB of both reopening and brief-opening $\mathrm{Na}^{+}$channels. As predicted, in the present study, salicylate significantly enhanced the quinidine-induced tonic block and UDB of both peak and steady-state $\triangle \mathrm{KPQ}$ currents. Interestingly, salicylate predominantly enhanced the quinidine-induced tonic block and UDB of steady-state $\triangle \mathrm{KPQ}$ currents and to a lesser extent those of peak $\triangle K P Q$ currents. Since the peak current of $\triangle \mathrm{KPQ}$ reflects fast inactivation (Mode $\mathrm{A}$ ), salicylate may only slightly increase quinidinebound inactivated $\triangle \mathrm{KPQ}$ at the current peak to decrease the peak amplitude of $\triangle \mathrm{KPQ}$ currents. On the other hand, the steady-state current of $\triangle \mathrm{KPQ}$ reflects channel reopening from the inactivated state (Mode B); thus, salicylate may dramatically increase quinidine-bound inactivated $\triangle \mathrm{KPQ}$ in the steady state, decreasing thereby the steady-state $\triangle \mathrm{KPQ}$ current.

\section{Acknowledgements}

This work was supported by Grant-in-Aid for the Scientific Research (C) of Ministry of Education, Science, Sports and Culture (I.H.) and Health Sciences Research Grants (Research on Pharmaceutical and Medical Safety) of Ministry of Health and Welfare (I.H.).

\section{REFERENCES}

1. Ahmmed GU, Hisatome I, Kurata Y, Makita N, Tanaka Y, Tanaka H, Okamura T, Sonoyama K, Furuse Y, Kato M, Yamamoto Y, Ogura K, Shimoyama M, Miake J, Sasaki N, Ogino K, Igawa O, Yoshida A and Shigemasa C (2002) Analysis of moricizine block of sodium current in isolated guineapig atrial myocytes. Atrioventricular difference of moricizine block. Vascul Pharmacol 38, 131-141.

2. An R-H, Bangalore SZ and Kass RS (1996) Lidocaine block of LQT-3 mutant human $\mathrm{Na}^{+}$channels. Circ Res 79, 103 108.

3. Chandra R, Starmer CF and Grant AO (1998) Multiple ef- 
fects of KPQ deletion mutation on gating of human cardiac $\mathrm{Na}^{+}$channels expressed in mammalian cells. Am J Physiol 274, H1643-H1654.

4. Clancy CE and Rudy Y (1999) Linking a genetic defect to its cellular phenotype in a cardiac arrhythmia. Nature 400, 566-569.

5. Hartmann HA, Tiedeman AA, Chen SF, Brown AM and Kirsch GE (1994) Effects of III-IV linker mutations on human heart $\mathrm{Na}^{+}$channel inactivation gating. Circ Res 75, 114 122.

6. Hartshorne RP and Catterall WA (1984) The sodium channel from rat brain. Purification and subunit composition. $J$ Biol Chem 259, 1667-1675.

7. Hiji Y, Miyoshi M, Ichikawa O, Kasagi T and Imoto T (1987) Enhancement of local anaesthesia action by organic acid salts. (I): Possible change of excitability in nerve fibre membrane. Arch Int Physiol Biochim 95, 113-120.

8. Hisatome I, Kurata Y, Sasaki N, Morisaki T, Morisaki H, Tanaka Y, Urashima T, Yatsuhashi T, Tsuboi M, Kitamura F, Miake J, Takeda S, Taniguchi S, Ogino K, Igawa O, Yoshida A, Sato R, Makita N and Shigemasa C (2000) Block of sodium channels by divalent mercury: Role of specific cysteinyl residues in the P-Loop region. Biophys $J$ 79, 1336-1345.

9. Hisatome I, Matsuoka S, Miyamoto J, Sawaguchi M, Omodani H, Osaki S, Kotake H, Mashiba H and Sato R (1990) Blocking effect of 1389-S on the sodium current in isolated guinea-pig ventricular myocytes. Eur J Pharmacol 179, 447-451.

10. Hisatome I, Miyamoto J, Hasegawa J, Kotake H, Mashiba H and Sato R (1988) Comparative study of the block of $V_{\max }$ by aprindine and quinidine in the guinea-pig heart muscle. Eur J Pharmacol 153, 285-288.

11. Hondeghem LM and Katzung BG (1984) Antiarrhythmic agents: the modulated receptor mechanism of action of sodium and calcium channel-blocking drugs. Annu Rev Pharmacol Toxicol 24, 387-423.

12. Kambouris NG, Nuss HB, Johns DC, Marban E, Tomaselli GF and Balser JR (2000) A revised view of cardiac sodium channel "blockade" in the long-QT syndrome. J Clin Invest 105, 1133-1140.

13. Katsuki H, Ibusuki S, Takasaki M, Nagata K and Hiji Y (1997) Monocarboxylic acids enhance the anesthetic action of procaine by decreasing intracellular pH. Biochim Biophys Acta 1334, 273-282.

14. Kiyosue T and Arita M (1989) Late sodium current and its contribution to action potential configuration in guinea pig ventricular myocytes. Circ Res 64, 389-397.

15. Messner DJ and Catterall WA (1985) The sodium channel from rat brain. Separation and characterization of subunits. $J$ Biol Chem 260, 10597-10604.
16. Miake J, Kurata Y, Iizuka K, Furuichi H, Manabe K, Sasaki N, Yamamoto Y, Hoshikawa Y, Taniguchi S, Yoshida A, Igawa O, Makita N, Shiota G, Nanba E, Ohgi S, Narahashi T and Hisatome I (2004) State-dependent blocking actions of azimilide dihydrochlo-ride (NE-10064) on human cardiac $\mathrm{Na}(+)$ channels. Circ J 68, 703-711.

17. Nagatomo T, January CT and Makielski JC (2000) Preferential block of late sodium current in the LQT3 $\triangle \mathrm{KPQ}$ mutant by the class 1c antiarrhythmic flecainide. Mol Pharmacol 57, 101-107.

18. Nuss HB, Tomaselli GF and Marbán E (1995) Cardiac sodium channels (hH1) are intrinsically more sensitive to block by lidocaine than are skeletal muscle $(\mu 1)$ channels. $J$ Gen Physiol 106, 1193-1209.

19. Patlak JB and Ortiz M (1985) Slow currents through single sodium channels of the adult rat heart. J Gen Physiol 86, 89104.

20. Patton DE, West JW, Catterall WA and Goldin AL (1992) Amino acid residues required for fast $\mathrm{Na}^{+}$-channel inactivation: charge neutralizations and deletions in the III-IV linker. Proc Natl Acad Sci USA 89, 10905-10909.

21. Ragsdale DS, McPhee JC, Scheuer T and Catterall WA (1994) Molecular determinants of state-dependent block of $\mathrm{Na}^{+}$ channels by local anesthetics. Science 265, 1724-1728.

22. Starmer CF and Grant AO (1985) Phasic ion channel blockade. A kinetic model and parameter estimation procedure. Mol Pharmacol 28, 348-356.

23. Tanaka Y, Hisatome I, Miyamoto J, Urashima T, Ikeda K, Yamanouchi Y, Sasaki N, Kinugawa T, Ogino K, Igawa O, Yoshida A, Shigemasa C, Kurata Y and Sato R (1999) Enhancing effects of salicylate on tonic and phasic block of $\mathrm{Na}^{+}$ channels by class 1 antiarrhythmic agents in the ventricular myocytes and the guinea pig papillary muscle. Biochim Biophys Acta 1418, 320-334.

24. Vassilev PM, Scheuer T and Catterall WA (1988) Identification of an intracellular peptide segment involved in sodium channel inactivation. Science 241, 1658-1661.

25. Wang GO, Russell C and Wang S-Y (2003) State-dependent block of wild-type and inactivation-deficient $\mathrm{Na}^{+}$channels by flecainide. J Gen Physiol 122, 365-374.

26. Wang DW, Yazawa K, Makita N, George AL Jr and Bennett PB (1997) Pharmacological targeting of long QT mutant sodium channels. J Clin Invest 99, 1714-1720.

27. Yatsuhashi T, Hisatome I, Kurata Y, Sasaki N, Ogura K, Kato M, Kinugasa R, Matsubara K, Yamawaki M, Yamamoto Y, Tanaka Y, Ogino K, Igawa O, Makita N and Shigemasa C (2002) L-cysteine prevents oxidation-induced block of cardiac $\mathrm{Na}^{+}$channel via interaction with heart-specific cysteinyl residues in the P-loop region. Circ J 66, 846-850. 